\title{
Milli-International Unit per Milliliter per Milligram per Kilogram
}

National Cancer Institute

\section{Source}

National Cancer Institute. Milli-International Unit per Milliliter per Milligram per Kilogram. NCI Thesaurus. Code C119398.

A unit of concentration (biologic activity) equal to one milli-international unit per milliliter, divided by milligrams per kilogram. 